JNS 04112

\title{
Probabilistic diagnosis of normal pressure hydrocephalus and other treatable cerebral lesions in dementia
}

\author{
D.W.J. Dippel and J.D.F. Habbema \\ Center for Clinical Decision Sciences, Erasmus University Medical School, Rotterdam, The Netherlands \\ (Received 20 October, 1992) \\ (Revised, received 19 April, 1993) \\ (Accepted 5 May, 1993)
}

Key words: Computed tomography; Decision analysis; Dementia; Hydrocephalus

\begin{abstract}
Summary
Clinical profiles of dementia patients, differing with respect to age, presence of gait abnormalities and urinary incontinence are discussed. Epidemiological data, subjective probabilities and clinical reasoning are used to predict a treatable cerebral lesion, i.e., an intracranial space occupying lesion or normal pressure hydrocephalus (NPH). Our calculations help in distinguishing clinically between demented patients who are, and who are not likely to benefit from computed tomography (CT) investigation for treatable lesions and, eventually, from cerebrospinal fluid shunting for NPH. Utility calculations show that shunting can be recommended only for a patient with the full triad of symptoms of NPH, and CT evidence of NPH, when no other prognostic information is available. Future clinical research should address the long-term prognosis of (treated) NPH patients, and the mortality of shunting, because these two factors are critical to the shunting decision.
\end{abstract}

\section{Introduction}

Although the number of publications on the management of normal pressure hydrocephalus (NPH) seems to be in decline more than 25 years since the first description of the syndrome (Hakim and Adams 1965; Friedland 1989), there is no consensus about its diagnosis and treatment (Clarfield 1989). Many patients who seem to have NPH do not respond to shunting, probably because irreversible damage has been done, or because these patients actually suffer from primary degenerative or multi-infarct dementia. As NPH is a clinically defined syndrome, a certain diagnosis cannot be made. We therefore propose a probabilistic approach to the diagnosis of NPH and other treatable cerebral lesions in demented patients. Clinical and pathological studies that investigated the

Correspondence to: D.W.J. Dippel, Department of Neurology, University Hospital Dijkzigt, Dr. Molewaterplein 40, 3015 GD Rotterdam, Netherlands. Tel.: 31-10-4633327; Fax: 31-10-4633208.

Abbreviations: AD, Alzheimer's disease; CT, computed tomography; SOL, space occupying lesion; MID, multi-infarct dementia; NPH, normal pressure hydrocephalus. occurrence of NPH and other treatable cerebral lesions in dementia have not systematically analyzed the diagnostic value of information obtained from history and physical examination (Wells 1978; Smith and Kiloh 1981; Bradshaw 1983; Dietch 1983). In the present study we combine epidemiological data, subjective probabilities and clinical reasoning in order to assess the impact of diagnostic features and age on the probability of NPH and of an intracranial space occupying lesion (SOL) in a demented patient, before and after computed tomography (CT). Decision analysis is used to weigh the risks and benefits of shunting for NPH and to give recommendations for the diagnostic and therapeutic management of demented patients who may suffer from this condition. The analysis is restricted to investigation with $\mathrm{CT}$, because this belongs to the standard diagnostic management of patients suspected of having NPH. The role of other diagnostic tools is less clear. Cisternography does not seem to add useful prognostic or diagnostic information (Børgesen 1984; Pickard 1984; Vanneste et al. 1992), but MRI may proof useful in the distinction between NPH and multi-infarct dementia (Chui et al. 1992). These two tools will not be considered here, for lack of evidence. The role of external lumbar drainage, lumbar puncture and continuous pressure monitoring will be discussed. 
TABLE: 1

CLINICAL PROFILES DIFFERING IN AGE, PRESENCE OF GAIT ABNORMALITIES AND URINARY INCONTINENCE. AND DURATION OF THE DEMENTIA

Key patient: bold text. All patients: Sixty-year-old white female, aged 60. Blood pressure: 155/95. Neurological examination: no dysphasia, no hemisyndrome, tendon reflexes brisk, but not abnormal. Muscle tone normal. Plantar responses flexor. No extrapyramidal signs. Laboratory: normal blood count and electrolytes. Thyroid, liver and renal function normal for age. No deficiencies of vitamin $B_{12}$ or folate. Syphilis tests negative. Urine analysis normal. Lumbar puncture: CSF pressure normal and no clinical improvement (by measurement or assumption).

\begin{tabular}{lllll}
\hline Profile & $\begin{array}{l}\text { Duration of } \\
\text { dementia } \\
\text { (years) }\end{array}$ & Age & $\begin{array}{l}\text { Urinary } \\
\text { incontinence }\end{array}$ & $\begin{array}{l}\text { Gait } \\
\text { abnormalities }\end{array}$ \\
\hline 1 & 0.5 & 60 & No & No \\
2 & $\mathbf{0 . 5}$ & $\mathbf{6 0}$ & No & Yes \\
3 & 0.5 & 60 & Yes & No \\
4 & 0.5 & 60 & Yes & Yes \\
\hline
\end{tabular}

\section{Patients and methods}

\section{Patients}

A fictitious patient will be used to illustrate the analysis. This 60-year-old woman had suffered for 6 months from memory difficulties and disorientation in time. On neurological examination there was a fairly typical shuffling gait, but no other (focal) abnormalities. There were no depressive symptoms. Mini Mental Score was 20/30 (Folstein et al. 1975). Details of physical, neurological and laboratory examinations are summarized in Table 1. Three other clinical profiles have been defined for comparison. They differ from the key patient with respect to the presence of gait abnormalities and urinary incontinence. These two features deserve some emphasis in our opinion because they are considered typical for patients with NPH, but their occurrence in patients with Alzheimer's disease (AD) or multi-infarct dementia (MID) may give rise to faulty diagnoses and consequently, failure to respond to shunting. In order to explore the effect of age on the likelihood of a treatable lesion 4 patients aged 75 with a similar clinical profile will be considered separately in the Results section. We did not consider treatable lesions in patients with dementia of longer duration, as their response to shunting is disappointing (Graff-Radford et al. 1989).

For the purpose of this study, dementia is defined as a syndrome of deterioration from a known or estimated prior level of intellectual function which is not isolated to a single narrow category of intellectual performance, and which is independent of level of consciousness (Chui et al. 1992). The relative frequency (in a hospital setting) of the 4 major cerebral causes of the dementia syndrome (i.e., NPH, intracranial SOL,
MID or $A D)$ will be used as an estimate of the prior probability of each cause of dementia. These disease entities do not refer to a clinically defined syndrome, but to a presumed underlying cause of dementia. Other causes of dementia and depression are considered to be ruled out. Several other conditions may lead to a clinical picture of dementia and gait abnormalities, for example dementia pugilistica, dementia associated with M Parkinson, chronic alcoholism and multiple sclerosis. Multiplicity of disease is not considered. Next, the occurrence of a 8 diagnostic features - all of which are obtainable by taking the patient's history and doing a physical examination - is assessed for each type of dementia. To this purpose the literature was searched systematically. 'Studies of the clinical picture of the 4 causes of dementia were selected when the final diagnosis was based on prolonged follow-up, or histo-pathological confirmation. Sometimes only semi-quantitative or no estimates at all concerning the occurrence of diagnostic signs in each of the 4 causes of dementia were available in the literature. In that case we resorted to subjective estimates, made by the first author of this study. 2 When exact data are not available plausible ranges for each point estimate were defined by taking a ratio for the upper and lower bounds of at least four. Then, a probability of each cause is computed for each patient using Bayes' rule, with a global association factor to adjust for conditional dependence between feature probabilities (Hilden and Bjerregaard 1976). A value of $2 / 3(1 / 2-1)$ is chosen, implying that we assume that 3 diagnostic features yield the same amount of information as 2 completely independent ones.

\section{Normal pressure hydrocephalus}

The syndrome of NPH consists of dementia, gait abnormalities, with or without urinary incontinence, in the presence of a dilated ventricular system, and 'normal' cerebro-spinal fluid pressure (Huckman 1981). In a large autopsy series of 164 pre-senile demented people $5.5 \%$ were diagnosed as NPH (Jellinger 1976). The diagnosis was based on the presence of severely dilated ventricles, thickened pia and arachnoidea, no pathologic evidence of $\mathrm{AD}$ and no other cause for the

\footnotetext{
1 A Medline search of the medical literature published since 1982 on epidemiology and diagnosis in DEMENTIA. ((PRE)SENILE), AlZHEIMER'S DISEASF, DEMENTIA VASCULAR, DEMENTIA MULTI INFARCT and HYDROCEPHALUS NORMAL PRESSURE was carried out. Out of the 2242 journal articles a further selection was made by scanning the abstract for the above-mentioned methodological aspects.

2 These subjective estimates were challenged by the second author, a senior researcher in clinical decision theory with special interest in the neurosciences, by a senior neurologist with long academic experience, and by an academically trained neurosurgeon.
} 
ventricular enlargement. In 270 senile demented patients the frequency of NPH was $0.7 \%$. The difference in relative frequency of NPH between senile and presenile demented patients (Table 2) (Katzman 1978) may be explained by the large number of people with $\mathrm{AD}$ at higher age (Pearce 1984; Ritchie 1992).

Many reports describe prognostic factors for successful shunting (Greenberg et al. 1977; Hughes et al. 1978; Meyer et al. 1985; Thomsen et al. 1986; GraffRadford et al. 1989), but in the majority of these reports the number of cases is small, follow-up short, the NPH syndrome loosely defined, criteria for success after shunting not explicit, and assessment of clinical status not independent of pre-operative status (Harris 1977; Katzman 1978; Huckman 1981; Anderson 1986). As gait abnormalities will be criterion for inclusion in most of the studies, its frequency cannot be reliably estimated. In one large study of patients considered for shunting it occurred in $95 \%$ of the cases (Larson et al. 1992). In studies where urinary incontinence was not a criterion for inclusion, this sign occurred in approximately $50 \%$ of patients (Udvarhelyi et al. 1975; Black 1980; Petersen et al. 1985). Slowness of thought and gesture are often mentioned. Focal signs are notably absent. Sometimes there are signs of cortico-spinal tract involvement. Extensor plantar responses have been found in 9 out of 16 patients (Fisher 1977), and in 15 of the 74 patients in Larsson's study. Pseudobulbar signs, including primitive reflexes (snout, palmo-mental or grasp-reflex), were found in $70 \%$ of the cases (Larsson et al. 1992).

\section{Intracranial space-occupying lesions}

In a large autopsy study $4 \%$ of the senile demented patients had an intracranial SOL, and a subdural hematoma was discovered in $1 \%$ of the patients (Jellinger 1976). Of the pre-senile demented patients $8.5 \%$ had a SOL and none had a chronic subdural haematoma (CSH). In non-demented patients aged less than 60 years CSH is not infrequent and the condition is well known for its frequent neuropsychological manifestations (Brihaye 1986). The absence of CSH in this age group in the autopsy study has to be explained by the alertness of physicians that leads to surgical drainage before dementia develops. In demented patients with a cerebral SOL, gait abnormalities are not uncommon. Fluctuations in the clinical course are may occur, because of edema or (focal) seizures.

\section{Multi-infarct dementia}

MID is a less common disorder than AD. The diagnostic term is used to designate dementia resulting from many large, cortical and subcortical infarcts and dementia resulting from small deep lacunar infarcts, which will not necessarily lead to similar clinical pictures (Drachman 1993; Román et al. 1993). Estimates of the relative frequency of MID show wide variation (Heyman 1978; Liston and La Rue 1983; Chui et al. 1992). In estimating the relative frequency of MID, many authors refer to Tomlinson et al. (1970). The author himself states that his sample "was not truly a random one and consequently, conclusions could not be drawn about the prevalence of the various types of dementing processes in old age". Thus, the relative frequency of MID is taken at $15 \%$, with a range of 5-45\% (Jellinger 1976; Kokmen et al. 1980; Chui et al. 1992).

In most studies the male/female ratio is $1: 1$ (Barclay et al. 1985; Del Ser et al. 1990). Common signs in MID are rigidity of the lower extremities, extensor plantar responses, gait abnormalities, and convulsions. We only found semi-quantitative estimates of the likelihood of these signs in the literature. Stepwise deterioration is noted as a typical feature of MID. History of stroke, which is common in MID, is not considered because it overlaps with stepwise deterioration. Signs of cortico-spinal tract involvement will be highly correlated, and therefore plantar responses only were considered. In a clinico-pathological study pseudo-bulbar signs and primitive reflexes occurred in $50-90 \%$ and urinary incontinence in $85 \%$ of the cases (Del Ser et al. 1990), However, it is quite likely that these clinical data were obtained late in the course of the disease, and therefore the frequency of these signs

TABLE 2

RELATIVE FREQUENCY OF NORMAL PRESSURE HYDROCEPHALUS, MULTI-INFARCT DEMENTIA, INTRACRANIAL SPACE OCCUPYING LESION AND ALZHEIMER'S DISEASE

\begin{tabular}{|c|c|c|c|c|}
\hline & \multicolumn{2}{|l|}{60 years } & \multicolumn{2}{|l|}{75 years } \\
\hline & $\begin{array}{l}\text { Point value } \\
(\%)\end{array}$ & $\begin{array}{l}\text { Plausible range } \\
(\%)\end{array}$ & $\begin{array}{l}\text { Point value } \\
(\%)\end{array}$ & $\begin{array}{l}\text { Plausible range } \\
(\%)\end{array}$ \\
\hline Normal pressure hydrocephalus (NPH) & 5.5 & $2.0-9.0$ & 1.0 & $0.0-2.0$ \\
\hline Intracranial space occupying lesion (SOL) & 8.5 & $4.5-12.5$ & 4.0 & $2.0-8.0$ \\
\hline Multi-infarct dementia (MID) & 15.0 & $5.0-45.0$ & 15.0 & $5.0-45.0$ \\
\hline Alzheimer's disease $(\mathrm{AD})$ & $\begin{array}{l}71.0+ \\
100\end{array}$ & $33.5-88.5$ & $\begin{array}{l}80.0+ \\
100\end{array}$ & $45.0-93.0$ \\
\hline
\end{tabular}


was estimated at $70 \%$ and $50 \%$, respectively. In another study with pathological confirmation stepwise deterioration had occurred in approximately $50 \%$, and focal signs were also noted in $50 \%$ of the cases (Mölsä et al. 1985). We decided not to use the complete (modified) Hachinski score (Hachinski 1978; Rosen et al. 1980), because it is not clear whether it is useful for discrimination of MID from other causes of dementia than AD (Heyman 1978; Liston and La Rue 1983; Molgaard 1987; Fischer et al. 1991).

\section{Alzheimer's disease}

The prevalence of (senile) dementia of the Alzheimer type in the elderly population has been estimated at 5-15\%, making it the most frequent cause of dementia in the elderly. Its relative frequency in series of demented patients varies heavily, because the diagnosis is established 'per exclusionem'.

In an early stage the disease is characterized by amnesia, disturbances of spatial orientation and lack of spontaneity (Pearce 1984). The male/female ratio is $1: 2$ (Pearce 1984; Barclay et al. 1985; Mölsä et al. 1985). The duration of this stage is approximately $2-4$ years. In his own series of more than 150 pre-senile demented patients, $20 \%$ had focal signs, predominantly dysphasia. Later, progressive dementia with typical focal features such as agnosia, apraxia and dysphasia, as
TABLE 3

FEATURE PROBABILITIES OF FOUR POSSIBLE CAUSES OF DEMENTIA (NPH, INTRACRANIAL SOL, MID AND AD)

Estimates that are based on (adjusted) data from the literature are designated with ${ }^{\mathrm{L}}$, estimates that are based on semi-quantitative information (from reviews mostly) are designated with ${ }^{\mathrm{R}}$, and estimates that are entirely subjective are designated with ${ }^{\mathrm{s}}$. For sources see text. Figures are rounded to the nearest $5 \%$.

\begin{tabular}{lcclc}
\hline & $\begin{array}{l}\text { NPH } \\
(\%)\end{array}$ & $\begin{array}{l}\text { SOL } \\
(\%)\end{array}$ & $\begin{array}{l}\text { MID } \\
(\%)\end{array}$ & $\begin{array}{c}\text { AD } \\
(\%)\end{array}$ \\
\hline Male gender & $50^{\mathrm{L}}$ & $50^{\mathrm{R}}$ & $50^{\mathrm{L}}$ & $33^{\mathrm{L}}$ \\
Stepwise deterioration & $10^{\mathrm{R}}$ & $30^{\mathrm{S}}$ & $90^{\mathrm{R}}$ & $10^{\mathrm{R}}$ \\
Gait abnormalities & $95^{\mathrm{I}}$ & $50^{\mathrm{S}}$ & $50^{\mathrm{R}}$ & $5 \mathrm{~L}$ \\
Urinary incontinence & $50^{\mathrm{L}}$ & $20^{\mathrm{s}}$ & $50^{\mathrm{I}}$ & $5 \mathrm{I}$ \\
Dysphasiá & $5 \mathrm{~L}$ & $10^{\mathrm{S}}$ & $25^{\mathrm{R}}$ & $25^{\mathrm{L}}$ \\
Extensor plantar responses & $25^{\mathrm{L}}$ & $50^{\mathrm{S}}$ & $50^{\mathrm{L}}$ & $5^{\mathrm{R}}$ \\
Pseudobulbar signs & $70^{\mathrm{L}}$ & $30^{\mathrm{S}}$ & $70^{\mathrm{L}}$ & $10^{\mathrm{R}}$ \\
Focal abnormalities & $5^{\mathrm{R}}$ & $60^{\mathrm{S}}$ & $50^{\mathrm{R}}$ & $5^{\mathrm{R}}$ \\
\hline
\end{tabular}

well as urinary incontinence and gait difficulties, develop (Table 3 .

\section{Computed tomography}

The sensitivity and specificity of CT investigation for several causes of dementia are determined and used to compute the probability of a treatable lesion when the

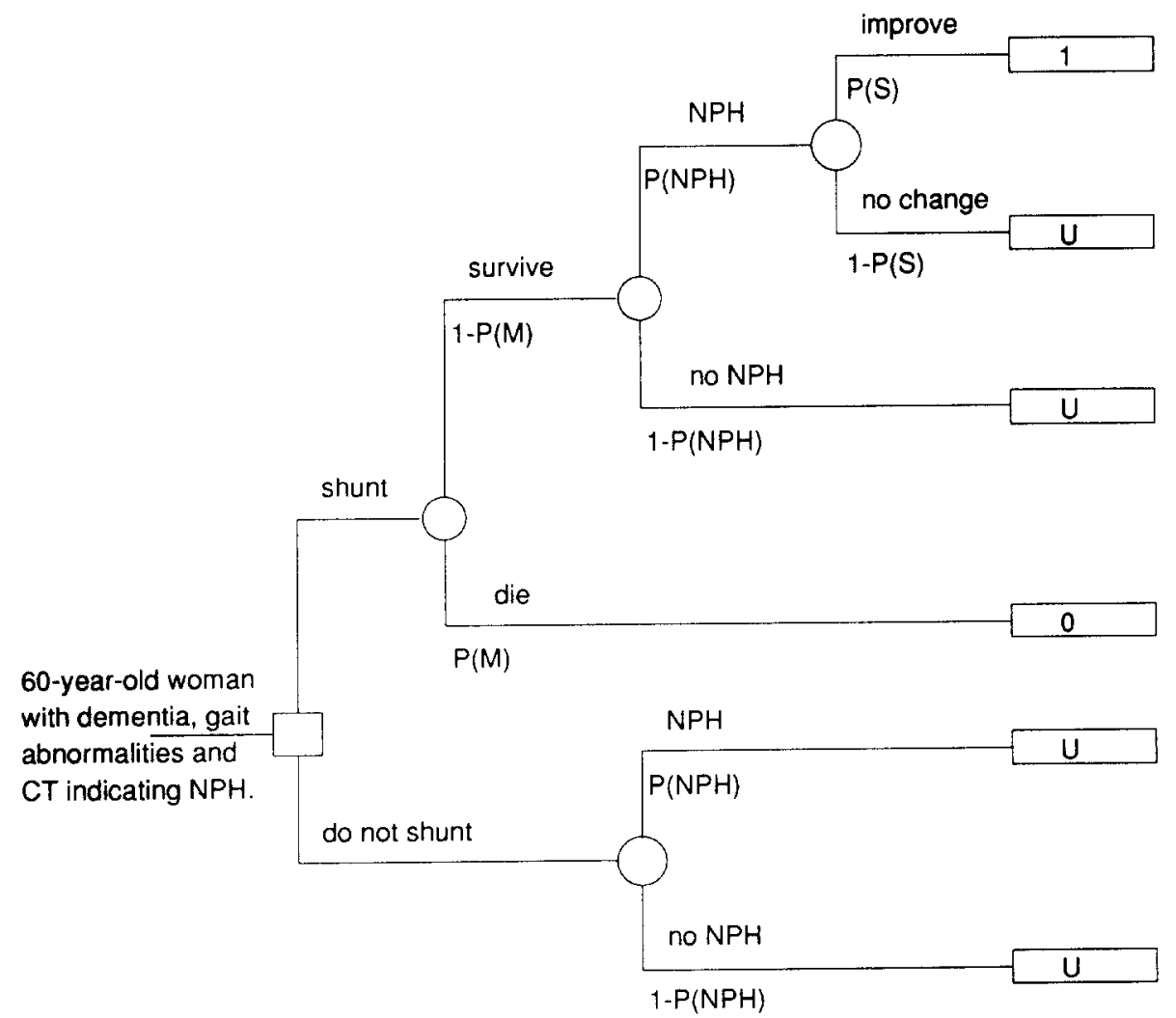

Fig. 1. Decision tree for the shunting decision in patients whose CT indicates NPH. $\square$, decision node; $\bigcirc$, chance node; $\square$, outcome node. Time flows from left to right. 
TABLE 4

DIAGNOSTIC PROBABILITIES FOR THE FOUR CLINICAL PROFILES FROM TABLE 1 OF THE FOUR CAUSES OF DEMENTIA BASED ON HISTORY AND PHYSICAL EXAMINATION, AND THE PROBABILITY OF NPH, WHEN THE CT INDICATES SUCH A LESION $(C T+)$, AND WHEN IT DOES NOT $(C T-)$

The last column gives the probability that the CT rightfully indicates any treatable lesion (SOL or NPH) on CT.

\begin{tabular}{|c|c|c|c|c|c|c|c|}
\hline \multirow[t]{2}{*}{ Profile } & \multicolumn{4}{|c|}{ Diagnostic probabilities } & \multicolumn{2}{|c|}{ Probability of NPH after CT } & \multirow{2}{*}{$\begin{array}{l}\text { Probability of a treatable } \\
\text { lesion on } C T \\
P(N P H \vee S O L, C T+)\end{array}$} \\
\hline & $\overline{\mathrm{NPH}}$ & SOL & MID & $\overline{\mathrm{AD}}$ & $\overline{P(N P H \mid C T+)}$ & $\overline{P(N P H \mid C T-)}$ & \\
\hline 1 & 0.005 & 0.02 & 0.005 & 0.97 & 0.01 & 0.00 & 0.02 \\
\hline 2 & 0.11 & 0.09 & 0.02 & 0.78 & 0.33 & 0.05 & 0.17 \\
\hline 3 & 0.02 & 0.04 & 0.02 & 0.92 & 0.13 & 0.01 & 0.06 \\
\hline 4 & 0.40 & 0.14 & 0.07 & 0.39 & 0.75 & 0.25 & 0.47 \\
\hline
\end{tabular}

CT results are known, and the overall probability of finding any treatable lesion by CT.

A diagnosis of probable Alzheimer type dementia is generally made after exclusion of other cerebral causes of dementia (Barclay and Blass 1985; LeMay 1986). Intracranial SOL will not be overlooked because they have to be rather large to cause global dementia. Artifacts are rare. Thus, both the sensitivity and specificity of CT for intracranial tumors that cause dementia will approach $100 \%$. The aspect of the CT abnormalities seen in dementia ranges from mainly cortical atrophy to frank ventricular enlargement, as seen in NPH (Gado et al. 1976). The sensitivity of CT for NPH (defined as the chance that CT indicates hydrocephalus when the patient really suffers from NPH) is about $70 \%$ and the specificity (defined as 1 minus the chance that CT indicates hydrocephalus when the patient suffers from MID or AD) will be approximately $80 \%$, when rigid criteria are applied (LeMay and Hochberg 1979; Tans 1979) ${ }^{3}$.

\section{Shunting for normal pressure hydrocephalus}

Not even all patients with definite NPH respond favorably to shunting. This can be concluded from studies of patients with NPH secondary to subarachnoid hemorrhage, meningitis, and intracranial surgery, in which diagnosis is beyond doubt (Katzman 1978). Consequently, if secondary and idiopathic NPH have a comparable response to treatment, a measure of the expected success rate when the diagnosis of NPH is uncertain can be derived by combining the probability of NPH with the probability of successful shunting in patients with secondary NPH.

\footnotetext{
${ }^{3}$ Tans' criteria for the CT diagnosis of NPH in a study of 62 demented patients are based on LeMay's study: (1) absence of cortical atrophy, (2) and at least 2 of the following: (a) FHR $>0.50$, (b) width of third ventricle $>3.5 \mathrm{~mm}$, (c) width of fourth ventricle $>4.0 \mathrm{~mm}$, (d) periventricular lucencies, (e) visibility of temporal horns. The final (gold standard) diagnosis was based on prolonged clinical observation.
}

The decision to shunt depends on the likelihood of $\mathrm{NPH}$, the chance of successful shunting, and the risk of complications from shunting (Harris 1977; Anderson 1986). Decision theory will be used to weigh these risks and benefits in order to identify which type of patient may be considered for shunting. The decision tree of Fig. 1 depicts the decision to shunt a patient with an uncertain diagnosis of NPH, based on history, physical examination and on the results of $C T$. Shunting carries a risk of mortality $(P(M))$, resulting in death with a utility of 0 . When the patient suffers from NPH (with a probability $P(N P H)$ ) and therapy is successful $(P(S))$, there will be lasting improvement of cognition. This outcome has a utility of 1 . When shunting is not successful, or when the patient's disease is not NPH, she will remain in a state of slowly progressive dementia, with a utility value $U$. The strategy do not shunt implies that the patient will remain in a state of slowly progressive dementia, also with a utility value $U$. Values of $U$ close to 0 imply that in the perception of a patient, or his representative, a large improvement can be made after successful shunting, and thus, they are more in favor of 'shunting' than values close to 1 .

In decision theory utility is defined as equal to the substitution probability $p$ when a decision maker is indifferent between an uncertain outlook with a chance $p$ of the best outcome (lasting improvement of cognition and ambulation after shunting), valued 1 , and a chance $(1-p)$ of the worst outcome (death), valued 0 , on the one hand, and on the other a certain outlook of slowly progressive dementia with utility $U$. There are several methods to elicit utilities (Torrance et al. 1987). We will by-pass this aspect by investigating a large range of values for $U$. However, even when utilities are not assessed directly, they have an inherent, intuitive meaning. When $U=0.75$, for example, this means that the patient is willing to take a mortality risk up to $1-0.75$, or $25 \%$, in order to be relieved from her dementia when operation is certainly successful (Weinstein et al. 1980; Von Winterfeldt 1986).

The chances of success after shunting in secondary 


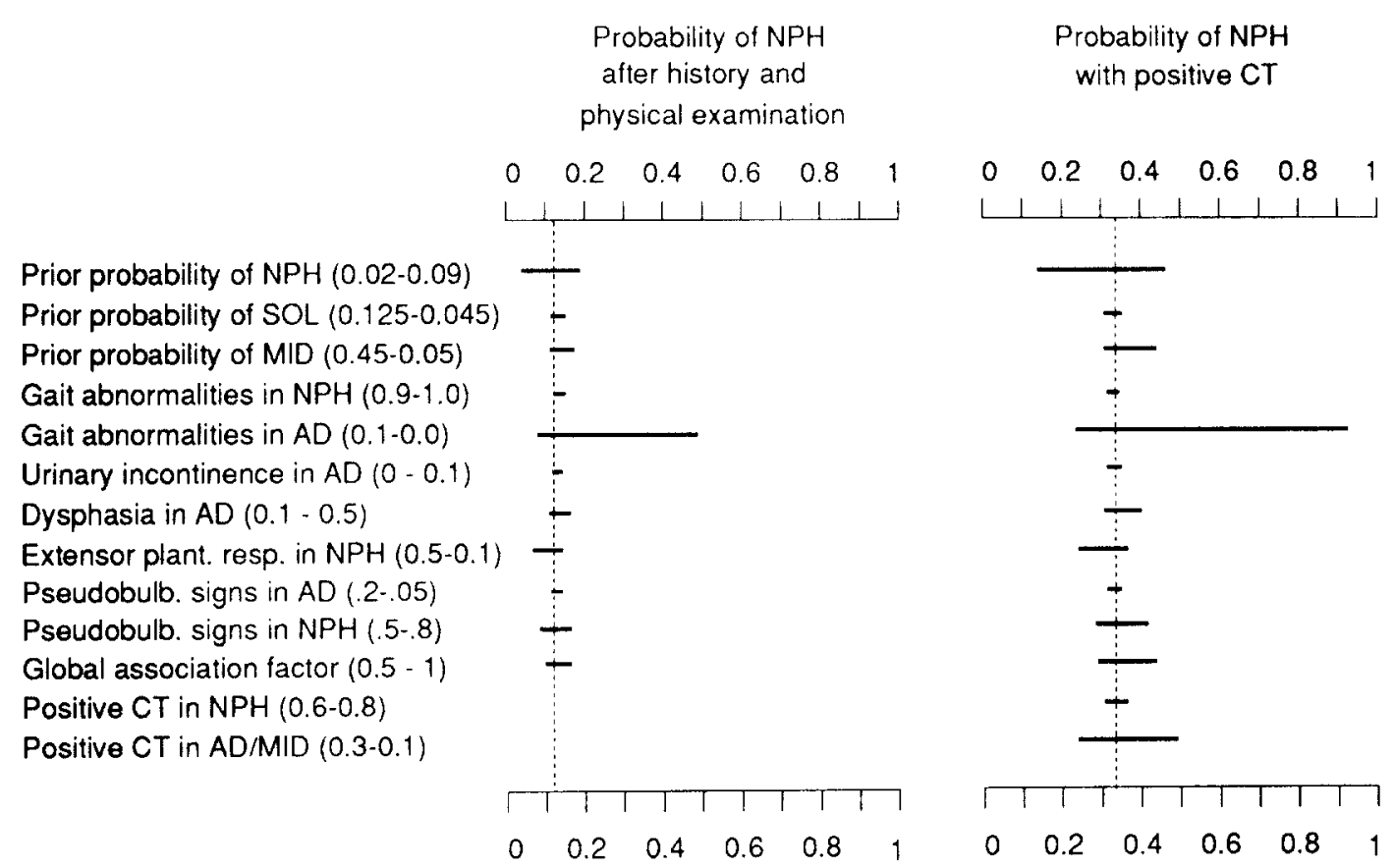

Fig. 2. Analysis of the sensitivity of the probability of NPH after history and physical examination and after a positive CT to plausible changes in estimates. This figure relates to the key patient (profile 2 of Table 1). The baseline estimate is 0.11 and 0.33 , respectively (Table 4).

$\mathrm{NPH}$ equal about $67 \%$ with a plausible range of 60 75\% (Katzman 1978; Børgesen 1984). Thus, the likelihood of successful shunting $(P(S))$ in our patient will amount to 0.67 times the chance of NPH after a positive $C T$. In most recent studies, the mortality associated with shunting is 4-9\% (Udvarhelyi et al. 1975; Greenberg et al. 1977; Spanu et al. 1986; Vanneste et al. 1992), somewhat lower than in older studies. However, for the purpose of this analysis mortality of shunt- ing $P(M)$ is taken at $10 \%$, in order to avoid the effects of publication bias (Sacket 1985).

\section{Results}

Diagnostic probabilities

The probability of NPH after history-taking and physical examination for the key patient amounts to

\begin{tabular}{|lc|}
\hline Diagnostic item & Score \\
\hline Stepwise deterioration & -10 \\
Male gender & +5 \\
Gait abnormalities & +44 \\
Urinary incontinence & +18 \\
Dysphasia & -17 \\
Extensor plant. resp. & +5 \\
Pseudobulbar signs & +21 \\
Focal signs & -13 \\
Age 60 & -70 \\
Age 75 & -91 \\
\hline Total (add) & \\
\hline
\end{tabular}

\begin{tabular}{|lll|}
\hline Score & Odds & Probability \\
\hline-90 & $1: 512$ & 0.002 \\
-60 & $1: 64$ & 0.015 \\
-40 & $1: 16$ & 0.059 \\
-30 & $1: 8$ & 0.111 \\
-20 & $1: 4$ & 0.20 \\
-15 & $1: 2.82$ & 0.262 \\
-10 & $1: 2$ & 0.33 \\
-5 & $1: 1.41$ & 0.414 \\
-2 & $1: 1.15$ & 0.465 \\
-1 & $1: 1.07$ & 0.483 \\
0 & $1: 1$ & 0.500 \\
1 & $1.07: 1$ & 0.517 \\
2 & $1.15: 1$ & 0.535 \\
5 & $1.41: 1$ & 0.586 \\
10 & $2: 1$ & 0.667 \\
15 & $2.82: 1$ & 0.738 \\
20 & $4: 1$ & 0.80 \\
30 & $8: 1$ & 0.889 \\
40 & $16: 1$ & 0.941 \\
60 & $64: 1$ & 0.985 \\
90 & $512: 1$ & 0.998 \\
\hline 0
\end{tabular}

Fig. 3. Algorithm for the probabilistic diagnosis of NPH in demented patients. When a sign is present, the corresponding number indicated by the left-hand table should be added to a total score. The right-hand table is used to convert this score (10 times the ${ }^{2}$ log-odds) via odds to probabilities. For every 10 points increase in total score, the odds for NPH double. To obtain the probability of NPH after a positive or negative CT, add 18 or -14 to the total score, respectively. 


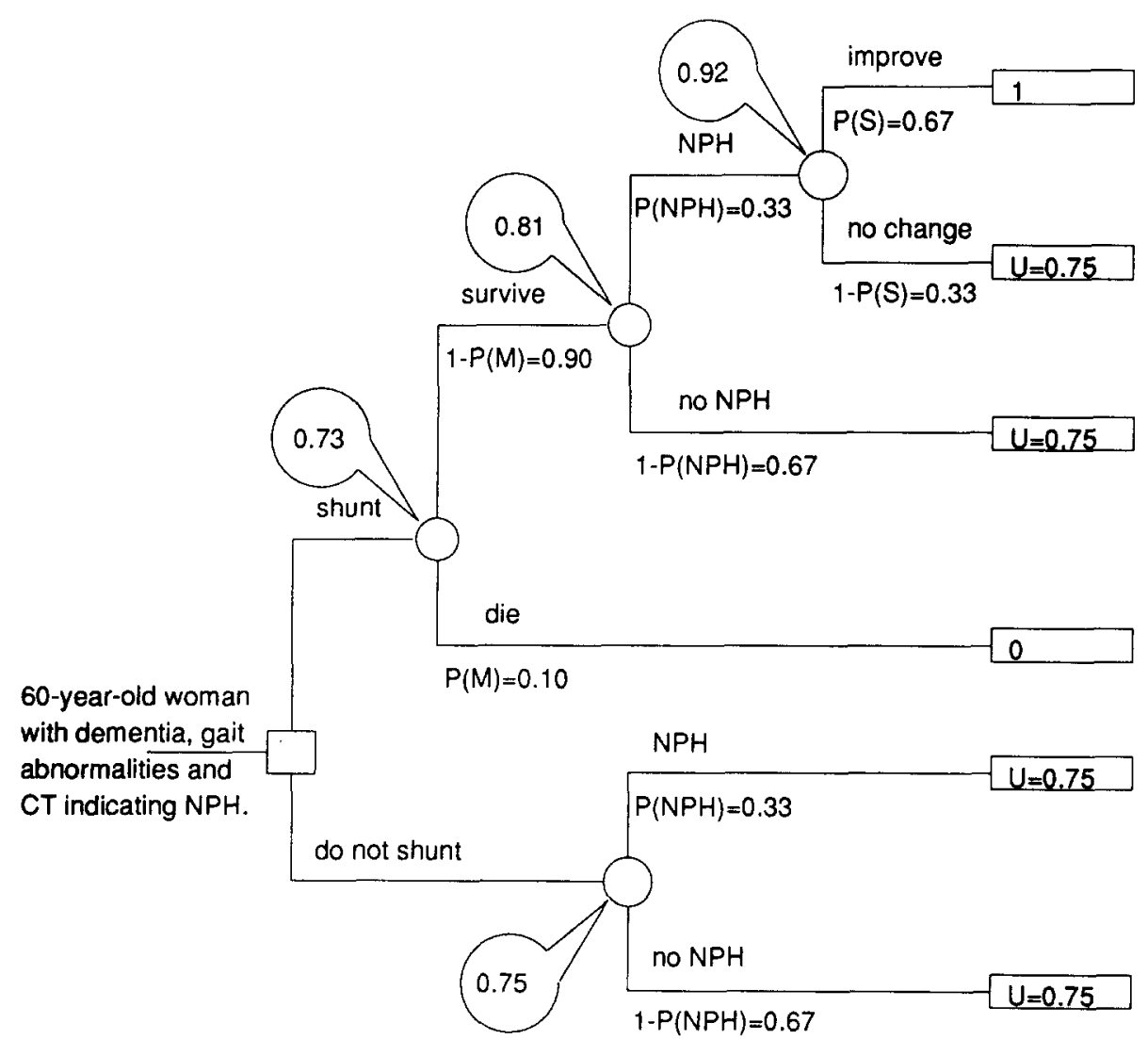

Fig. 4. Decision tree for the shunting decision in patients whose CT indicates NPH. All probability and utility values that are applicable to patient 2 have been inserted. Folding back the tree results in an expected utility of 0.73 for shunting, and 0.75 for no shunting.

$11 \%$ (Table 4). In profiles 1 and 3 the absence of gait abnormalities decreases the likelihood of NPH considerably. The diagnostic probability of an intracranial SOL in the key patient is $9 \%$, and it ranges from 2 to $14 \%$ for the different clinical profiles. The probabilities of NPH when this condition is and is not suggested by $\mathrm{CT}$, and the probability that the patient harbors any neurosurgically treatable lesion (a SOL or NPH) and the CT shows it $(P(N P H) \vee S O L, C T+))$, is also listed in Table 4 for each clinical profile.

In Fig. 2 an analysis of these results to plausible changes in the estimates is shown for the key patient. Changes in the prior probability of NPH and of gait abnormalities in $\mathrm{AD}$ influence the diagnostic probability considerably.

In order to make generalizations to other clinical profiles, we constructed a diagnostic chart, using the log-odds form of Bayes theorem (Fig. 3). ${ }^{4}$ This chart allows one to estimate the likelihood of NPH in a certain patient, before and after CT. The effects of age on the diagnostic probabilities is also incorporated. In

\footnotetext{
${ }^{4}$ Because of rounding, and because we took the weighted average of the diagnostic probabilities for the other causes of dementia, the results of Fig. 3 are accurate within 5\%.
}

patients aged 75 , the same ordering of the diagnostic probabilities as in profiles $1-4$ emerges, but the probability of a treatable lesion is lower and does not exceed $15 \%$.

\section{Decision analysis of shunting for NPH}

In Fig. 4 expected utilities of shunting and no shunting are computed for the key patient by 'folding back' the decision tree. The difference between the two strategies is small, with a slight benefit for no shunting in the key patient.

The decision tree is also evaluated using a threshold technique (Pauker and Kassirer 1980). Fig. 5 shows which combinations of values for the mortality of shunting and the probability of success after shunting result in equal expected utilities for both treatment options. These 'break-even' lines are plotted for various levels of $U$, see also the Methods section. This figure illustrates which patients will and which patients will not benefit from shunting, according to the expected utility criterion. For patients with profiles 1 and 3 , finding evidence for NPH on CT should not lead to shunting, even when the utility $U$ of dementia is taken at 0.5 of the utility of recovery. For the key patient (profile 2) a clear-cut preference does not seem to exist in the present analysis, but when the utility of demen- 


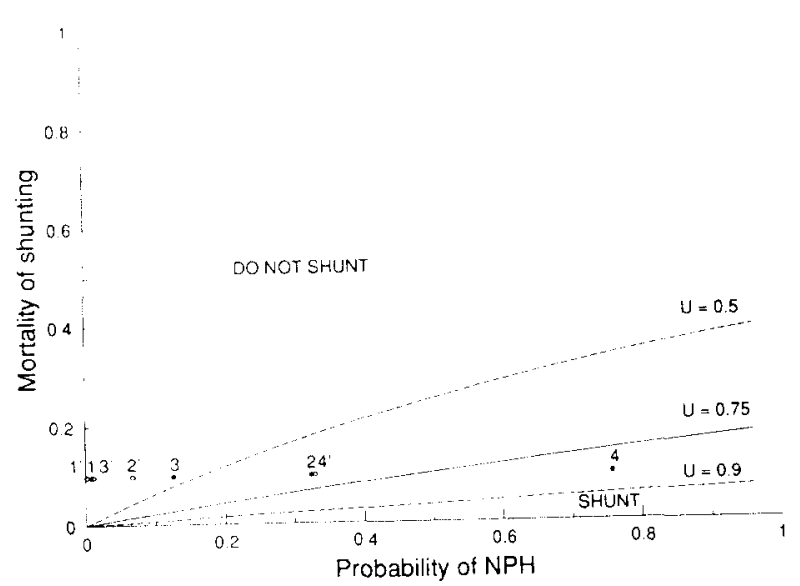

Fig. 5. Break-even lines for the shunting decision in patients suspected of NPH. $X$ axis: probability of successful shunting in a patient whose CT indicates NPH. $Y$ axis: mortality of shunting. The lines depict the combinations of values that result in equal expected utilities for the 'do not shunt' and 'shunt' decision in the tree of Fig. I, for various levels of the utility of dementia, $U$. Below each threshold line shunting is preferred, above each line no shunting. Clinical profiles of 60-year-old patients are indicated by black dots numbered $1-4$, and clinical profiles of 75 -year-old patients by open dots numbered $1^{\prime}-4^{\prime}$ (see also Table 4).

tia equals 0.5 , shunting is preferred (see also the Methods section for the interpretation of utility values). But for someone with a profile like patient 4 shunting seems to be beneficial. This conclusion is based on clinical information and CT results, but it may be modified by other prognostic test results (e.g., conductance to outflow measurement, or external lumbar drainage) (Wikkels $\emptyset$ et al. 1982; Børgesen 1984; Pickard 1984; Haan and Thomeer 1988).

\section{Discussion}

We estimated the likelihood of NPH and intracranial SOL in demented patients with a typical clinical profile. Based on these estimates, the chance of successful shunting for NPH was assessed. Decision analysis was used to weigh the risks and benefits of shunting in each patient.

This paper is based on the scientific evidence that is currently available. Where information is sparse, conclusions of a decision analysis can only be tentative. This does not imply that a quantitative approach should be abandoned, but rather that the analysis has been useful in identifying areas of clinical knowledge that would (if expanded) contribute much to better decision making in dementia. Particularly, estimates of the relative frequency of $\mathrm{AD}$ and related disorders, and of the frequency of diagnostic signs and symptoms are seldom reported in the literature. The data in this analysis seemed reasonable estimates to the authors when they considered the scarce evidence. This means that the results of this study should be applied to other patients with skill and caution.

The analysis has a normal cerebrospinal fluid pressure as a fixed assumption. This does not mean that patients are required to undergo a lumbar puncture before its results can be consulted. On the contrary, our tables and figures help surveying the clinical situation that will exist in the - likely - event that the pressure is normal. In this way, they contribute to the decision whether a CT, or any other major diagnostic procedure. is worthwhile.

Our method of analysis has its limitations. In the computations we used binary tests (indicating absence or presence of a sign or symptom). We did not allow for intermediate observations. Also, diagnostic features do not occur independently. This will influence the reliability of the computed values, if no corrections are made. We have tried to overcome these problems by sensitivity analyses (Fig. 2) and by using a global association factor. It is clear that we have chosen for maximum simplicity. In our opinion, taking more diagnostic features into consideration would not add much to the usefulness of the model because these feature probabilities would even be harder to quantify and dependence between features would become a greater problem.

Our analysis helps in distinguishing between patients who are likely to benefit from shunting and those who are not. The threshold approach (Fig. 5) suggests that only a relatively young patient with dementia of recent onset, the full triad of symptoms and CT evidence of NPH should be considered for shunting, if no additional prognostic information is available. For a patient of older age with the full triad and for a 60-year-old patient with only gait abnormalities and dementia a toss-up situation exists (see Fig. 5). More prognostic information might be of importance for these patients. Obviously, for the other patients, the finding of ventricular enlargement on CT - suggesting $\mathrm{NPH}$ - should not have any consequences.

Results of other prognostic tests may be of value, especially for patients with a profile like the key patient. When a patient improves in cognition or gait after a diagnostic lumbar puncture, the chances of successful shunting are high, but this phenomenon is rare, and when there is no clinical effect successful shunting is still quite likely (Pickard 1984). Conductance to outflow measurement may be of value. However, the results of the group of Børgesen (1984) have not been reproduced by others (Graff-Radford 1989). Moreover, the additional prognostic value of this test over more easily obtainable clinical information is not clear. The same argument holds for external lumbar drainage and continous pressure monitoring. To our knowledge, the value of both tests has never been assessed in a prospective, independent study. SPECT 
scanning may render useful information, but its prognostic value is suggested in one study only (Graff-Radford et al. 1989).

Our general recommendations will not surprise those who have followed or participated in the discussion of the management of NPH in the literature. However, the recommendations from our decision model have a rational basis. The assumptions are easy to identify and are open for discussion. Estimates can be adjusted to personal insight and to the results of other prognostic tests, and the consequences of these changes can easily be assessed. Moreover, application of the model leads to a more individualized decision, which takes patient characteristics into account in a controlled way.

The analysis can be helpful in comparing the value of pieces of diagnostic information. For example, the absence of gait abnormalities in a demented patient is important; it makes NPH an unlikely diagnosis. When interpreting a CT of a such patient one should be aware that NPH and successful shunting remain unlikely, even when hydrocephalus appears to be present.

Dietch observed that in dementia patients without special features the rate of treatable lesions is very small (Dietch 1983). Vanneste et al. (1993) already emphasized the importance of clinical signs for the prognosis after shunting in NPH patients. In his retrospective follow-up study, the proportion of patients with permanent overall improvement in the categories with 'probable', 'possible' and 'improbable' NPH according to a global clinical/CT scale was $65 \%, 15 \%$ and $13 \%$, respectively. However, clinical and CT criteria were informally weighed and lumped together in one scale, making more detailed conclusions impossible.

In our opinion more information on the specificity of clinical signs such as gait abnormalities, urinary incontinence, slowness and apathy in $\mathrm{AD}$ and related disorders is needed.

In the diagnostic and therapeutic management of a dementia patient the clinician has to rely on experience and intuition to manage the large amount of information that arises from clinical findings, knowledge, and the literature. We do not suggest that our approach should be used instead of the approved methods of clinical reasoning. But we think that we have shown that a formal, quantitative approach is useful in the differential diagnosis and management of dementia patients.

\footnotetext{
Acknowledgements Dr. J. Hilden (Department of Medical Genetics (Biostatistics), University of Copenhagen, Denmark), Dr. H. van Crevel (Department of Neurology, Academisch Medisch Centrum, Amsterdam, Netherlands) and Dr. E.J. Delwel (Department of Neurosurgery, University Hospital Dijkzigt, Rotterdam) made valuable comments on earlier versions of this manuscript. This study was supported in part by a grant from The Netherlands Health Research Promotion Programme (SGO).
}

\section{Appendix}

Bayes' theorem is used to convert the prior probability of each of the 4 considered causes of dementia $C_{i}$ to a posterior probability, based on information contained in the absence or presence of diagnostic features $D F$.

$$
P\left(C_{i} \mid D F\right)=\frac{\mathrm{P}\left(\mathrm{C}_{\mathrm{i}}\right) \times P\left(D F \mid C_{i}\right)}{\sum_{j=1}^{4} P\left(C_{j}\right) \times P\left(D F \mid C_{j}\right)}
$$

$D F$ stands for the 8 'diagnostic features' from history and physical examination that are considered (see Table 3 ). The probability of a particular combination of $D F$ is computed by taking the product of all the individual feature probabilities, $P\left(D_{k} \mid C_{j}\right)$, with $k=$ 1,2.8:

$$
P\left(D F \mid C_{j}\right)=\prod_{k=1}^{8} P\left(D_{k} \mid C_{j}\right)
$$

In order to adjust for the assumption of conditional independence, which is implied by Bayes theorem, a global association factor $(X, 0 \leqq X \leqq 1)$ is used (9):

$$
\begin{gathered}
P\left(D F \mid C_{j}\right) \infty\left(\prod_{k=1}^{8} P\left(D_{k} \mid C_{j}\right)\right)^{x} . \\
(' \infty \text { ' = 'proportional to') }
\end{gathered}
$$

A value of $1 / 8$ for $X$ implies that diagnostic probabilities are completely dependent, a value of $1 / 2 \mathrm{im}$ plies pairwise dependence, and a value of 1 implies complete independence. Likewise, a value of $2 / 3$ (as is used in this study) means that every 3 diagnostic items yield the information of 2 completely independent ones.

The log-odds form of Bayes theorem is used to compute a score that can be converted to posterior likelihoods:

$$
\begin{aligned}
\text { Score }= & 10 \times{ }^{2} \log \left(\frac{P\left(C_{i} \mid D F\right)}{1-P\left(C_{i} \mid D F\right)}\right) \\
= & { }^{2} \log \left(\frac{P\left(C_{i}\right)}{1-P\left(C_{i}\right)}\right) \\
& +\sum_{k=1}^{8}{ }^{2} \log \left(\frac{P\left(D_{k} \mid C_{i}\right)}{P\left(D_{k} \mid \bar{C}_{i}\right)}\right) \times X,
\end{aligned}
$$


where the subscore associated with each diagnostic feature $j$ in Table 4 is computed by taking

$$
\text { Subscore }_{j}={ }^{2} \log \left(\frac{P\left(D_{j} \mid C_{i}\right)}{P\left(D_{j} \mid \bar{C}_{i}\right)}\right) \times X
$$

and $P\left(D_{j} \mid \bar{C}_{i}\right)$ is taken as the average of the diagnostic probabilities in the 3 other causes, weighted with their priors, and $X$ is the global association factor.

The likelihood of successful shunting $S$ in a patient suspected of NPH is computed by taking the product of the probability of successful shunting in patients who have secondary NPH with certainty, and the probability of 'idiopathic' or 'primary' NPH in the patients considered in this paper:

$$
\begin{aligned}
P\left(S \mid C T^{+}, D F\right)= & P(S \mid N P H) \\
& \times P\left(N P H \mid C T^{+}, D F\right) .
\end{aligned}
$$

The next equation gives the algebraic representation of the decision tree in Fig. 1, for the special case where the expected utilities of each option are equal to each other:

$$
\begin{aligned}
E U(\text { Wait })= & E U(\text { Shunt }) \leftrightarrow \\
U= & (1-P(M)) \cdot(P(N P H)) \cdot P(S) \\
& +P(N P H) \cdot(1-P(S)) \cdot U \\
& +(1-P(N P H)) \cdot U) .
\end{aligned}
$$

By solving this equation for $P(M)$ we may obtain the value of the shunting mortality that results in equal expected utilities for Wait and Shunt, as a function of the probability of NPH $(P(N P H)$ ) (see Fig. 4).

$$
P(M)=1-\frac{U}{P(N P H) \times P(S) \times(1-U)+U}
$$

\section{References}

Anderson, M. (1986) Normal pressure hydrocephalus (Editorial). Br. Med. J., 293: 837-838.

Barclay, L.L. and Blass, J.P. (1985) Evaluation and treatment of the cognitively impaired patient. In: A.N.J. Exton-Smith (Ed), Practical Geriatric Medicine. Churchill Livingstone, Edinburgh.

Barclay, L.L., Zemcov, A., Blass, J.P. and Sansone, J. (1985) Survival in Alzheimer's disease and vascular dementias. Neurology 35: 834-840.

Black, P.M. (1980) Idiopathic normal pressure hydrocephalus. J. Neurosurg., 52: 371-377.
Børgesen, S.E. (1984) Conductance to outflow in normal pressure hydrocephalus. Acta Neurochir., 17: 1-45.

Bradshaw, J.R. (1983) Computed tomography in the investigation of dementia. Br. Med. J., 286: 277-280.

Brasey, D.-L., Fankhauser, H. and De Tribolet, N. (1988) Hydrocéphalie à pression normale chez l'adulte. Analyse de résultats et complications après dérivation ventriculo-cardiaque. Schweiz Med. Wschr.. 118: 919-923.

Brihaye, J. (1986) Chronic subdural hematoma. Adv. Neurotraumatol. 1: $101-156$.

Chui. H.C., Victoroff, J.I., Margolin, D., Jagust, W., Shankle, R. and Katzman, R. (1992) Criteria for the diagnosis of ischemic vascular dementia proposed by the State of California Alzheimer's Disease Diagnostic and Treatment Centers. Neurology, 42: 473-480.

Chui, H.C. (1989) Dementia: a review emphasizing clinicopathologic correlation and brain-hehaviour relationships. Arch. Neurol.. 46: $806-814$.

Clarfield, A.M. (1989) Normal pressure hydrocephalus: Saga or swamp?. JAMA. 262: 2592-93.

Crockard, H.A., Hanlon, K., Duda, E.E. and Mullan. J.F. (1977) Hydrocephalus as a cause of dementia: evaluation by computerised tomography and intracranial pressure monitoring. J. Neurol. Neurosurg. Psychiat., 40: 736-740.

Del Ser, T., Bermejo, F.. Arredondo, J.M.. Bouras, C. and Constantinidis, J. Vascular dementia. A clinicopathological study. J. Neurol. Sci., 96: 1-17.

Dietch, J.T. (1983) Computerized tomographic scanning in cases of dementia. West J. Med., 138: 835-837

Drachman, D.A. (1993) New criteria for the diagnosis of vascular dementia. Neurology, 43: 243-245.

Fischer, P., Jellinger, K., Gatterer, G. and Danielzeck, W. (1991) Prospective neuropathological validation of Hachinski's Ischaemic Score in Dementias. J. Neurol. Neurosurg. Psychiat., 54: $580-583$.

Fisher. M.C. (1977) The clinical picture in occult hydrocephalus. Clin Neurosurg., 24: 270-284.

Folstein, M.F., Folstein, S.E. and McHugh, P.R. (1975) 'MINI MENTAL STATE' A practical method for grading the cognitive state of patients for the clinician. J. Psychiat. Res., 12: 189-198.

Friedland, R.P. (1989) Normal-pressure hydrocephalus and the saga of the treatable dementias. JAMA, 262: 2577-2581.

Gado, M.H., Coleman, R.E., Lee, K.S., Wikhael, M.A., Alderson, P.O. and Archer, C.R. (1976) Correlation between computerized transaxial tomography and radionuclide cisternography in dementia. Neurology, 26: $555-560$.

Graff-Radford, N.R., Goderskey, J.C. and Jones, M.P. (1989) Variables predicting surgical outcome in symptomatic hydrocephalus in the elderly. Neurology. 39: 1601-1604.

Greenberg, J.D., Shenkin, H.A. and Adam, R. (1977) Idiopathic normal pressure hydrocephalus. A report of 73 patients. J. Neurol., 40: $36-341$

Haan. J. and Thomeer, R.T.W.M. (1988) Predictive value of temporary external lumbar drainage in normal pressure hydrocephalus. Neurosurgery. 22: 388-391.

Hachinski, V. (1978) Cerebral blood flow: Differentiation of Alzheimer's disease from multi infarct dementia. In: R. Katzman and R.D. Terry (Eds.), Alzheimer's Disease: Senile Dementia and Related Disorders. Raven Press, New York, pp. 97-103.

Hakim, S. and Adams, R.D. (1965) The special clinical problem of symptomatic hydrocephalus with normal cerebrospinal fluid pressure. Observations on cerebrospinal fluid hemodynamics. J. Neurol. Sci., 2: 207-327.

Harris, A.B. (1977) Summary of panel on choice of patients with dementia and normal pressure hydrocephalus for shunting. Clin. Neurosurg., 24: 334-336.

Heyman, A. (1978) Differentiation of Alzheimer's disease from multi infarct dementia. In: R. Katzman and R.D. Terry (Eds.) 
Alzheimer's Disease: Senile Dementia and Related Disorders. Raven Press, New York, pp. 109-113.

Hilden, J. and Bjerregaard, B. (1976) Computer aided diagnosis and the atypical case. In: F.T. de Dombal and F Grémy (Eds.), Decision Making and Medical Care: Can information Science Help?. North Holland Publ., Amsterdam.

Huckman, M.S. (1981) Normal pressure hydrocephalus: Evaluation of diagnostic and prognostic tests. Am. J. Neuroradiol., 2: 385395.

Hughes, C.P., Siegel, B.A., Coxe, W.S., Gado, M.H., Grubh, R.L. and Coleman, R.E. (1978) Adult idiopathic communicating hydrocephalus with and without shunting. J. Neurol., 41: 961-971.

Janny, P., Colnet, G., Veyre, A., Chazal, J. and Barreto, L.C. (1981) Hydrocéphalie à pression normale. Etude pré- et postopératoire de 56 cas. Neurochirurgie, 27: 89-96.

Jellinger, K. (1976) Neuropathological aspects of dementias resulting from abnormal blood and cerebrospinal fluid dynamics. Acta Neurol. Belg., 76: 83-102.

Katzman, R. (1978) Normal pressure hydrocephalus. In: R. Katzman and R.D. Terry (Eds.), Alzheimer's Disease: Senile Dementia and Related Disorders. Raven Press, New York, pp. 115-124.

Kokmen, E., Okazaki, H. and Schoenberg, B.S. (1980) Epidemiological patterns and clinical features of dementia in a defined US population. Trans. Am. Neurol. Assoc., 105: 334-336.

Larsson, A., Wikkelsö, C., Bilting, M. and Stephensen, H. (1992) Clinical parameters in 74 consecutive patients shunt operated for normal pressure hydrocephalus. Acta Neurol. Scand., 84: 475-482.

Laws, E.R. and Mokri, B. (1977) Occult hydrocephalus: Results of shunting correlated with diagnostic tests. Clin. Neurosurg., 24: 316-333.

LeMay, M. and Hochberg, F.H. (1979) Ventricular differences between hydrostatic hydrocephalus and hydrocephalus ex vacuo by computed tomography. Neuroradiology, 17: 191-195.

LeMay, M. (1986) CT changes in dementing diseases. A review. Am. J. Neuroradiol., 7: 841-853.

Liston, E.H. and La Rue, A. (1983) Clinical differentiation of primary degenerative and multi infarct dementia. Biol. Psychiat., 18: $1451-1484$

Meyer, J.S., Kitagawa, Y., Tanahashi, N., Tachibana, H., Kandula P. and Cech, D.A. (1985) Evaluation of treatment of normal pressure hydrocephalus. J. Neurosurg., 62: 513-521.

Molgaard, C.A. (1987) Multivariate analysis of Hachinski's scale for discriminating Senile Dementia of the Alzheimer's Type from multi infarct dementia. Neuroepidemiology. 6: 153-160.

Mölsä, P.K., Paljärvi, L., Rinne, J.O. and Säkö, E. (1985) Validity of clinical diagnosis in dementia: a prospective clinico-pathological study. J. Neurol. Neurosurg. Psychiat., 48: 1085-1090.

Pauker, S.G. and Kassirer, J.P. (1980) The threshold approach to clinical decision making. N. Engl. J. Med., 302: 1109-1117.

Pearce, J.M.S. (1984) Dementia, a Clinical Approach. Blackwell, Oxford.

Petersen, R.C., Mokri, B. and Laws, E.R. (1985) Surgical treatment of idiopathic hydrocephalus in elderly patients. Neurology, 307311.

Pickard, J.D. (1984) Normal pressure hydrocepahlus - to shunt or not to shunt? In: C. Warlow and J. Garfield (Eds.), Dilemmas in the Management of the Neurological Patient. Churchill Livingstone, Edinburgh.
Ritchie, K., Kildea, O. and Roline, J.-M. (1992) The relationship between age and the prevalence of senile dementia. A meta-analysis of recent data. Int. J. Epidemiol., 21: 763-769.

Román, G.C., Takemichi, T.K., Erkinjuntti, T., Cummings, J.L., Maseu, J.C., Garcia, J.H., Amaducci, L., Orgogozo, J.-M., Brun, A., Hofman, A., Moody, D.M., O'Brien M.D., Yamaguchi, T., Grafman, J., Drayer, B.P., Bennett, D.A., Fisher, M., Ogata, J., Kokmne, E., Bermejo, F., Wolf, P.A., Gorelick, P.B., Bick, K.L., Pajeau, A.K., Bell, M.A., DeCarli, C., Culebras, A., Korczyn, A.D., Bogousslavsky, J., Hartmann, A. and Scheinberg, P. (1993) Vascular dementia: diagnostic criteria for research studies. Neurology, 43: 250-260.

Rosen, W.G., Terry, R.D., Fuld, P.A., Katzman, R. and Peck, A. (1980) Pathological verification of ischemic score in differentiation of dementias. Ann. Neurol., 486-488.

Sackett, D.L., Haynes, R.B. and Tugwell, P. (1985) Clinical epidemiology. Little Brown, Boston, MA.

Salmon, J.H. (1972) Adult hydrocephalus. Evaluation of shunt therapy in 80 patients. J. Neurosurg., $37: 423-428$.

Smith, J.S. and Kiloh, L.G. (1981) The investigation of dementia: results in 200 consecutive admissions. Lancet, 824-827.

Spanu, G., Sangiovanni, G. and Locatelli, D. (1986) Normal-pressure hydrocephalus: twelve years experience. Neurochirurgia, 29: 1519.

Tans, J.T.J. (1979) Differentiation of normal pressure hydrocephalus and cerebral atrophy by computed tomography and spinal infusion test. J. Neurol., 222: 109-118.

Thomsen, A.M., Borgesen, S.E., Bruhn, P. and Gjerris, F. (1986) Prognosis of dementia in normal pressure hydrocephalus after a shunt operation. Ann. Neurol, 20: 304-310.

Tomlinson, B.E., Blessed, G. and Roth, M. (1970) Observations on the brains of demented old people. J. Neurol. Sci., 11: 205-242.

Torrance, G.W. (1987) Utility approach to measuring health-related quality of life. J. Chron. Dis., 40: 593-600.

Udvarhelyi, G.B., Wood, J.H., James, A.E. and Bartelt, D. (1975) Results and complications in 55 shunted patients with normal pressure hydrocephalus. Surg. Neurol., 3: 271-275.

Vanneste, J., Augustijn, P., Dirven, C., Tan, W.F. and Goedhart, Z.D. (1992) Shunting normal-pressure hydrocephalus: Do the benefits outweigh the risks? A multicenter study and literature review. Neurology, 1992;42: 54-59.

Vanneste, J., Augustijn, P., Tan, W.F. and Dirven, C. (1993) Shunting normal pressure hydrocephalus: the predictive value of combined clinical and CT data. J. Neurol. Neurosurg. Psychiat., 56: 251-256.

Von Winterfeldt, D. and Edwards, W. (1986) Decision Analysis and Behavioral Research. Cambridge University Press, Canbridge.

Weinstein, M.C., Fineberg, H.V., Elstein, A.S., Frazier, H.S., Neuhauser, D., Neutra, R.R. and McNeil, B.J. (1980) Clinical Decision Analysis. WB Saunders, Philadelphia, PA.

Wells, C.E. (1978) Chronic brain disease: An overview. Am. J. Psychiat., 135: 1-12.

Wikkelsø Anderson, H., Blomstrand, C. and Lindqvist, G. (1982) The clinical effect of lumbar puncture in normal pressure hydrocephalus. J. Neurol. Neurosurg. Psychiat., 45: 64-69. 